\title{
Modelling the water mass exchange through navigational channels connecting adjacent coastal basins - application to the Channel of Potidea (North Aegean Sea)
}

\author{
Y. G. Savvidis ${ }^{1}$, C. G. Koutitas ${ }^{2}$, and Y. N. Krestenitis ${ }^{2}$ \\ ${ }^{1}$ Department of Fisheries and Aquaculture, Technological Educational Institute of Thessaloniki, N. Moudania, 63200 \\ Chalkidiki, Greece \\ ${ }^{2}$ Division of Hydraulics and Environmental Engineering, Department of Civil Engineering, Aristotle University of \\ Thessaloniki, 54006 Thessaloniki, Greece
}

Received: 10 February 2004 - Revised: 12 July 2004 - Accepted: 9 November 2004 - Published: 28 February 2005

\begin{abstract}
The research objective is the detection of the mechanism of the water mass exchange through a navigational channel connecting two adjacent coastal basins. The research involves the application of a mathematical model in parallel to in-situ measurements. The hydrodynamic circulation in the greater area of the NW Aegean Sea is modeled by means of a barotropic circulation model. Wind, Coriolis and Tide are the main forcings taken into account. The flow through the channel is resolved at a subgrid scale by means of a local open channel flow model. The comparison between field measurements, recorded during a limited period, and the model results supports the model verification. The study is integrated by an operational application of the model under various realistic forcings. The results help to gain a better understanding of the mechanisms regulating the water mass exchange and the consequent interaction between two adjacent connected coastal basins. From the case study of the Potidea channel it is revealed that the water mass exchange under mean wind forcing is of the same order as the one induced by the tidal forcing.
\end{abstract}

Key words. Oceanography, physical (currents, sea level variations) - Oceanography, general (numerical modelling)

\section{Introduction}

Two adjacent coastal basins, connected through a navigational channel, form a dynamical system characterized by mutual water and particulate matter exchange and intermixing. An integrated study of such a hydrodynamic system can be realised with the combination of mathematical modelling and fieldworks. Successful examples of modelling studies (i.e. development and application of models for the study of the hydrodynamic circulation of the seawaters, as well as the transport of particulate matter) include works published by Koutitas (1987), Blumberg and Mellor (1987), Valioulis

Correspondence to: Y. G. Savvidis

(savvidis@civil.auth.gr) and Krestenitis (1994), Drakopoulos and Laskaratos (1999), Krestenitis et al. (2000), Kourafalou (1999, 2001), Savvidis et al. (2001), Pinardi et al. (2003) and Kourafalou et al. (2004). Furthermore, field measurements based on the valuable contribution of electronic oceanographic instruments have also been successfully conducted by Laskaratos et al. (1990), Krestenitis et al. (2000), Ursella and Gacic (2001) and Pinardi et al. (2003) for the study of the marine environment worldwide.

The objective of this paper is to present a procedure for the study of the water mass exchange that takes place through a navigational channel connecting two adjacent coastal basins. This water mass transport may influence the water quality of the two adjacent gulfs and is related to the depositional problems of a channel, due to transport of suspended sediments, which is a very serious issue for the navigation through a channel. This environmental and morphological influence, with its socioeconomic consequences, constituted a basic reason for the initial study of this water mass exchange as a first step/approach to a general study, which should follow. As a case study, the water mass exchange through the Potidea Channel, connecting the Toroneos and Thermaikos Gulfs, in the North Aegean Sea, (East Mediterranean Sea) is studied in detail for the first time, by the use of mathematical modelling combined with field measurements The two gulfs are depicted in Fig. 1, which also shows the whole area and the bathymetry of the North Aegean Sea.

The water depths of the greater basin vary from very shallow along the coastal zones up to maximum depths reaching $1350 \mathrm{~m}$. However, the main part of the two gulfs is characterized by relatively shallow waters. Axios, Loudias, Aliakmonas and Pinios are the main rivers in the area, flowing into the west part of the Thermaikos Gulf. During the last decades, the river discharges decreased steadily due to the operation of hydroelectric plants and irrigation projects. Minimal river discharges of the order of some $\mathrm{m}^{3} / \mathrm{s}$ have been observed during the summer period and recorded between 1997 and 1998 by Karamanos and Polyzonis (1998). Besides, according to Krestenitis et al. (1997), the rivers of the 


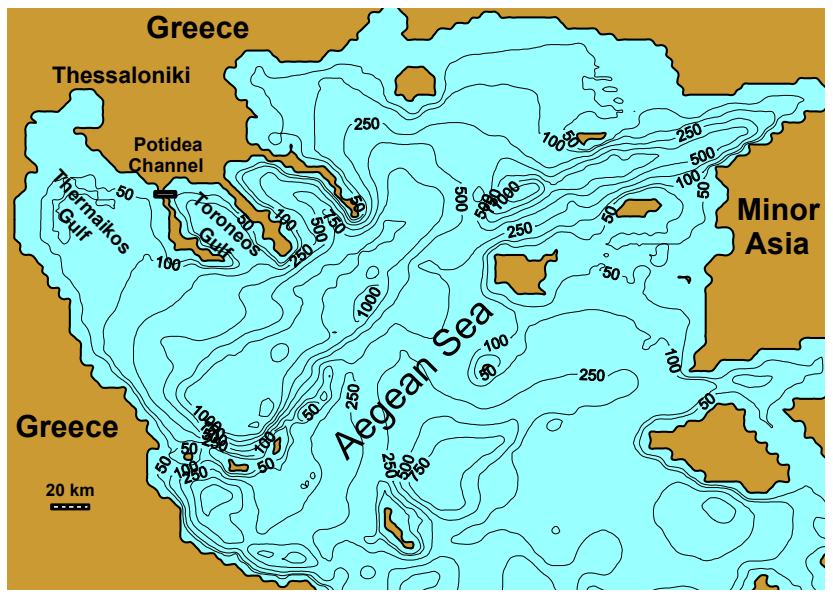

Fig. 1. The Northern Aegean Sea the, modeled area and the Potidea channel.

west coasts of Thermaikos, mainly influence the north part of the inner Thermaikos Gulf, while they can hardly affect the east coasts, where the channel lies. It is also important to note that there are not significant rivers or other sources of fresh water input in both areas, close to the west and east side of the channel. Consequently, the influence of the river water discharges, especially to the summer water circulation in the Thermaikos Gulf, is not important, and is therefore neglected in the present study. A more detailed illustration of the study area of the two adjacent gulfs and the channel, connecting the two basins, is given in Fig. 2.

The Potidea Channel is an artificial navigational channel connecting the Thermaikos and Toroneos Gulfs. This channel allows the water mass exchange and the consequent transport and intermixing between the two adjacent gulfs. For the estimation of the geometrical characteristics of the channel, field measurements are made. The channel cross section is approximated with a trapezoid. The channel length is $1100 \mathrm{~m}$ $(L=1100 \mathrm{~m})$ while the mean channel width on the surface is taken equal to $40 \mathrm{~m}(W=40 \mathrm{~m})$. The depth of the channel varies between 3.5 and $5.5 \mathrm{~m}$, with a mean value of $4.5 \mathrm{~m}$ $(D=4.5 \mathrm{~m})$. A sketch of the typical cross section of the channel is given in Fig. 3.

At the beginning of the present work, a current recorder was installed at a representative cross section of the channel in order to record current velocity and direction for certain time periods. Repeated model runs, under specific wind forces, corresponding to the real meteorological conditions during the field measurements were then conducted. The tidal influence was modeled in parallel. The results of the model in combination with the field data ensured the validity of the particular methodology. The study was integrated by the application of the model for all the wind directions (eight directions), and the mean wind velocity. The tidal signals that reach the basins of Thermaikos and Toroneos Gulfs are semidiurnal, with a mean tidal range equal to $0.25 \mathrm{~m}$. Furthermore, barometric pressure gradients between the channel ends are obviously negligible due to the small extension of

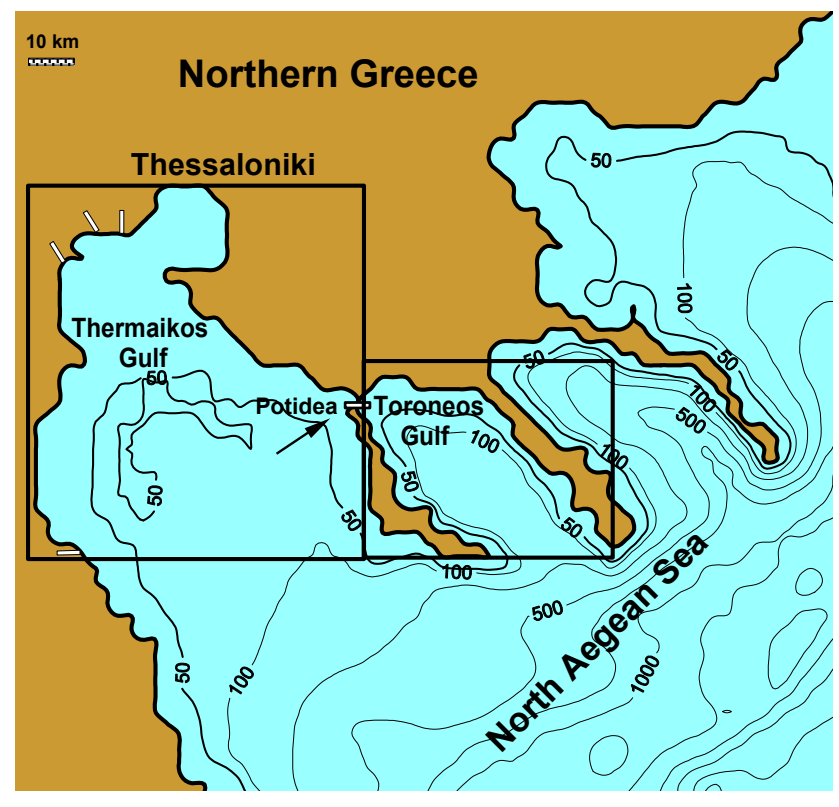

Fig. 2. The greater study area with the two gulfs and the particular area of the Potidea channel (the arrow marks the channel.

the channel. The seawater density differences could not constitute an important reason for the generation of the circulation and water mass exchange through the channel because the eastern part of the Thermaikos Gulf has similar temperature and salinity characteristics as the western part of the Toroneos Gulf. Therefore, it is expected that the sea level difference between the two adjacent gulfs is mainly caused by the wind and tidal forcing.

Consequently, we consider the hydrodynamic circulation of the channel area as barotropic, even if the circulation in the extended area of the whole basin is baroclinic. Thus in this study we use a 2-D hydrodynamic model.

More specifically, the numerical modelling of the hydrodynamic conditions over a large portion of the sea area is used to compute the velocity and surface elevation field over the two gulfs and the surface elevation differences across the channel. The sea level difference is then used for the study of the water transport through the channel and the consequent water mass exchange between the two gulfs.

\section{Design of the modeling approach}

The overall modelling approach consists of two discrete steps. The first step refers to the hydrodynamic modelling of the large scale of the North Aegean Sea. For the computation of the water circulation over the greater basin (containing the two gulfs), the wet part of the channel is considered as dry land. So, the free surface elevation on the two sides (right and left) from the narrow part of the land, where the channel lies, is initially computed.

The next step refers to the small scale of the channel. At this step the channel is no longer considered as land. For 
the hydraulic computation of the open channel, the sea level difference/variation between the two ends constitutes the key point for the computation of the mean velocity of the currents, as well as the flow rate through the channel. The above approach is based on the fact that the feedback of the mass exchanged through the channel on the formation of the circulation patterns is considered as negligible. The modelling work is supplemented by in-situ measurements that support the model results. The description of the hydraulics and the modelling approach, as well as the field measurements, is given in the following paragraphs.

As the main hydrodynamic parameter, regulating the water exchange between the two basins through the connecting channel, is the free surface elevation; the hydrodynamic circulation in the two shallow coastal basins is described by the application of a 2-D H hydrodynamic model. The governing equations, based on the well-known principles of momentum and mass conservation and corresponding to a homogeneous medium, are given below:

$\frac{\partial U}{\partial t}+U \frac{\partial U}{\partial x}+V \frac{\partial U}{\partial y}=-g \frac{\partial \zeta}{\partial x}+f V+\frac{\tau_{s x}}{\rho h}-\frac{\tau_{b x}}{\rho h}+v_{h} \frac{\partial^{2} U}{\partial x^{2}}+v_{h} \frac{\partial^{2} U}{\partial y^{2}}$

$\frac{\partial V}{\partial t}+U \frac{\partial V}{\partial x}+V \frac{\partial V}{\partial y}=-g \frac{\partial \zeta}{\partial y}-f U+\frac{\tau_{s y}}{\rho h}-\frac{\tau_{b y}}{\rho h}+v_{h} \frac{\partial^{2} V}{\partial x^{2}}+v_{h} \frac{\partial^{2} V}{\partial y^{2}}$

$\frac{\partial \zeta}{\partial t}+\frac{\partial(U h)}{\partial x}+\frac{\partial(V h)}{\partial y}=0$

where $h$ is the water depth, $U$ and $V$ are the depth-averaged horizontal velocities, $\zeta$ is the surface elevation, $f$ is the Coriolis parameter (here $10^{-4} \mathrm{~s}^{-1}$ ), $\tau_{s x}$ and $\tau_{s y}$ are the wind shear stresses, with

$\tau_{s x}=\rho \times C_{s} \times W_{x} \times \sqrt{W_{x}^{2}+W_{y}^{2}}$

$\tau_{s y}=\rho \times C_{s} \times W_{y} \times \sqrt{W_{x}^{2}+W_{y}^{2}}$.

$W_{x}$ and $W_{y}$ are the wind velocity components, $C_{S}$ is the surface friction coefficient with values of the order of $10^{-6}$ (here $\left.2 \times 10^{-6}\right), \tau_{b x}$ and $\tau_{b y}$ are the bottom shear stresses, with

$\tau_{b x}=\rho \times C_{b} \times U \times \sqrt{U^{2}+V^{2}}$

$\tau_{b y}=\rho \times C_{b} \times V \times \sqrt{U^{2}+V^{2}}$,

where the bottom friction coefficient is computed according to the following Von Karman relationship

$\left.C_{b}=\left[0,4 / \ln \left[h / z_{o}\right]-1\right)\right]^{2}$,

where $z_{o}$ is the height of bed roughness $\left(z_{o}=1 \mathrm{~cm}\right), v_{h}$ is the horizontal eddy diffusion coefficient related, according to Smagorinsky, to the local vorticity gradient, $\rho$ is the mean seawater density, equal to $1025 \mathrm{~kg} / \mathrm{m}^{3}$, and $g$ is the gravity acceleration.

For the wind-generated circulation, the Somerfield radiation boundary condition is adopted on the south and east open sea boundaries. For the case of the tidal-generated circulation, the total surface elevation along the south open boundary is estimated as a superposition of an incoming periodical

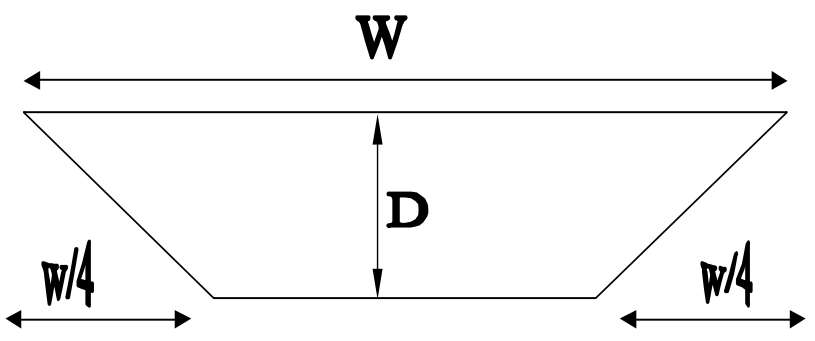

Fig. 3. Geometrical characteritics of a typical cross section of the channel.

signal and a radiated one, while a free radiation condition was adopted on the east open sea boundary. The flow field is discretised horizontally by a $70 \times 67$ grid, with mesh size $D x=2.5 \mathrm{~km}$. The time step is $D t=10 \mathrm{~s}$, on the grounds of the well-known Courant Criterion $(D t<D x / \sqrt{2 g h}$, where $h$ is the maximum water depth). A classical explicit difference scheme on a staggered grid is used for the solution of the mass and momentum conservation equations.

Following the computation of the surface level elevation differences on the two ends of the channel, the mean velocity $\mathrm{u}_{m}$ and the rate of the water mass exchange through the channel $\mathrm{Q}_{m}$ are computed by the well- known Manning equation, which, for the case of steady uniform flow in an open channel, takes the following form:

$u_{m}=\frac{1}{n} \times R^{2 / 3} \times J^{1 / 2}$

and

$Q_{m}=A \times u_{m}$,

where $R$ is the hydraulic radius, $J$ the energy gradient or the free surface slope of the flow (equal to the $\Delta \zeta / L$, i.e. the computed elevation difference between the two ends of the channel divided by the length of the channel $L$ ), $\mathrm{n}$ is an empirical bed roughness coefficient, and $A$ is the area of a cross section of the channel.

Fieldworks were also made in order to support the overall modelling study. More specifically, a current recorder was employed for the in-situ measurements of the current velocity and direction. The instrument was installed under the road bridge, where the water depth is $D=3.7 \mathrm{~m}$. This specific cross section is considered as a representative typical section of the channel. The instrument was placed $1 \mathrm{~m}$ below the sea surface. Both the velocity and the direction of the current are recorded. These data allowed for the computation of the water mass exhange between the Thermaikos and Toroneos Gulfs through the Potidea Channel.

\section{In-situ measurements - application of the model}

\subsection{In-situ measurements}

The specific study was focused on the modelling of the water mass exchange through channels connecting two adjacent 

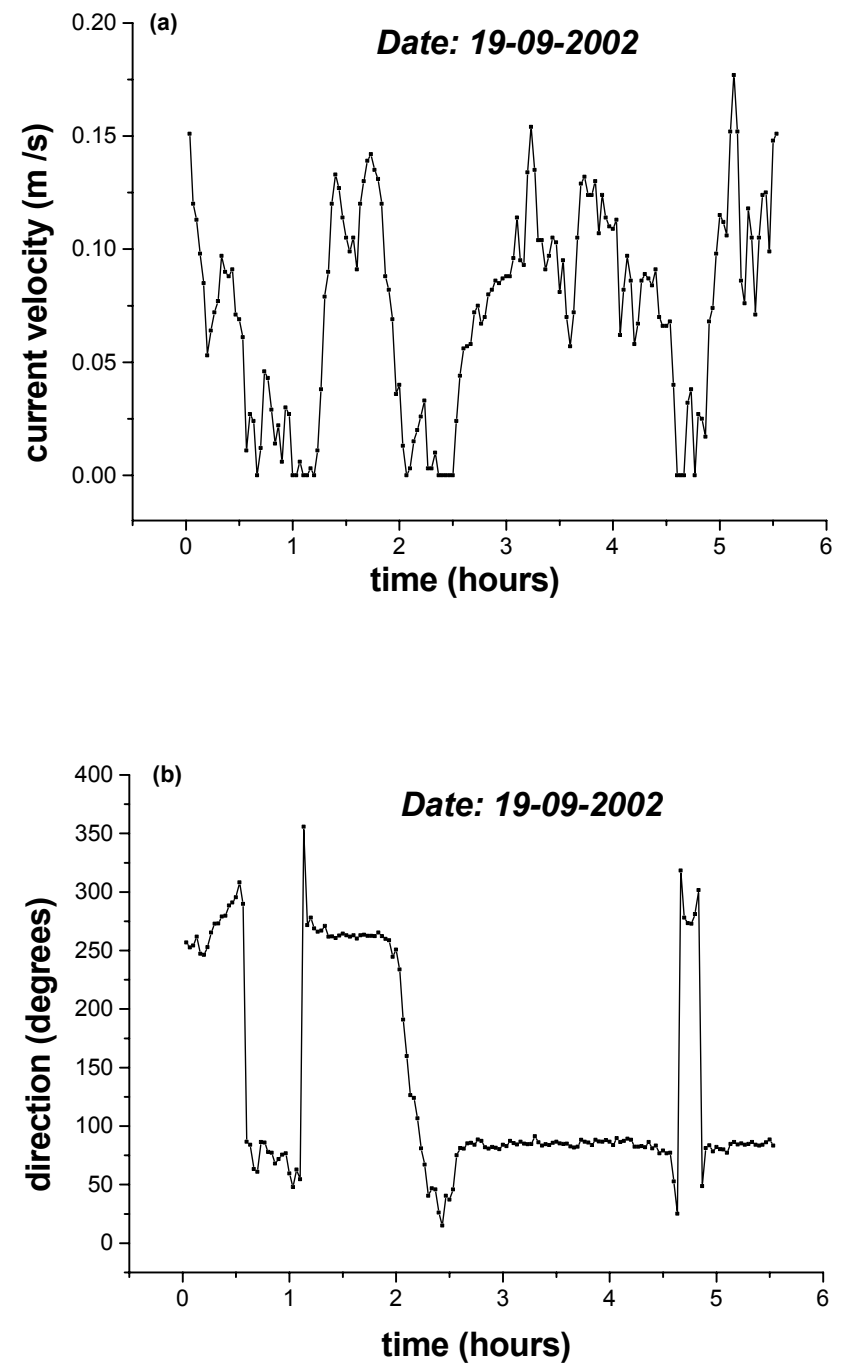

Fig. 4. (a) Current velocity versus time (19 September 2002), (b) Current direction versus time (19 September 2002).

coastal basins, with an application to the channel of Potidea (NW Aegean Sea). The collection of a short data set was considered as a useful tool for the calibration/validation of the modelling results.

The first set of the field measurements was collected on 19 September 2002 between 14:00 and 20:00 while the second one was on 22 September 2002 between 12:00 and 18:00. During the first day of the field measurements the wind was northwest (NW) while during the second day the wind was southeast (SE). The recorded time series are depicted in the following diagrams (Figs. 4a and 4b, 5a and 5b). The diagrams show the current velocity and the current direction versus time.

As far as the current direction is concerned, it is confined along the channel axis with values from 75 to $275^{\circ}$. Sudden changes from the first to the second direction are due to the changes in the sea levels on the channel ends. Considering that the $0^{\circ}$ corresponds to a southerly current, i.e. current heading to the north, the following observations are made:
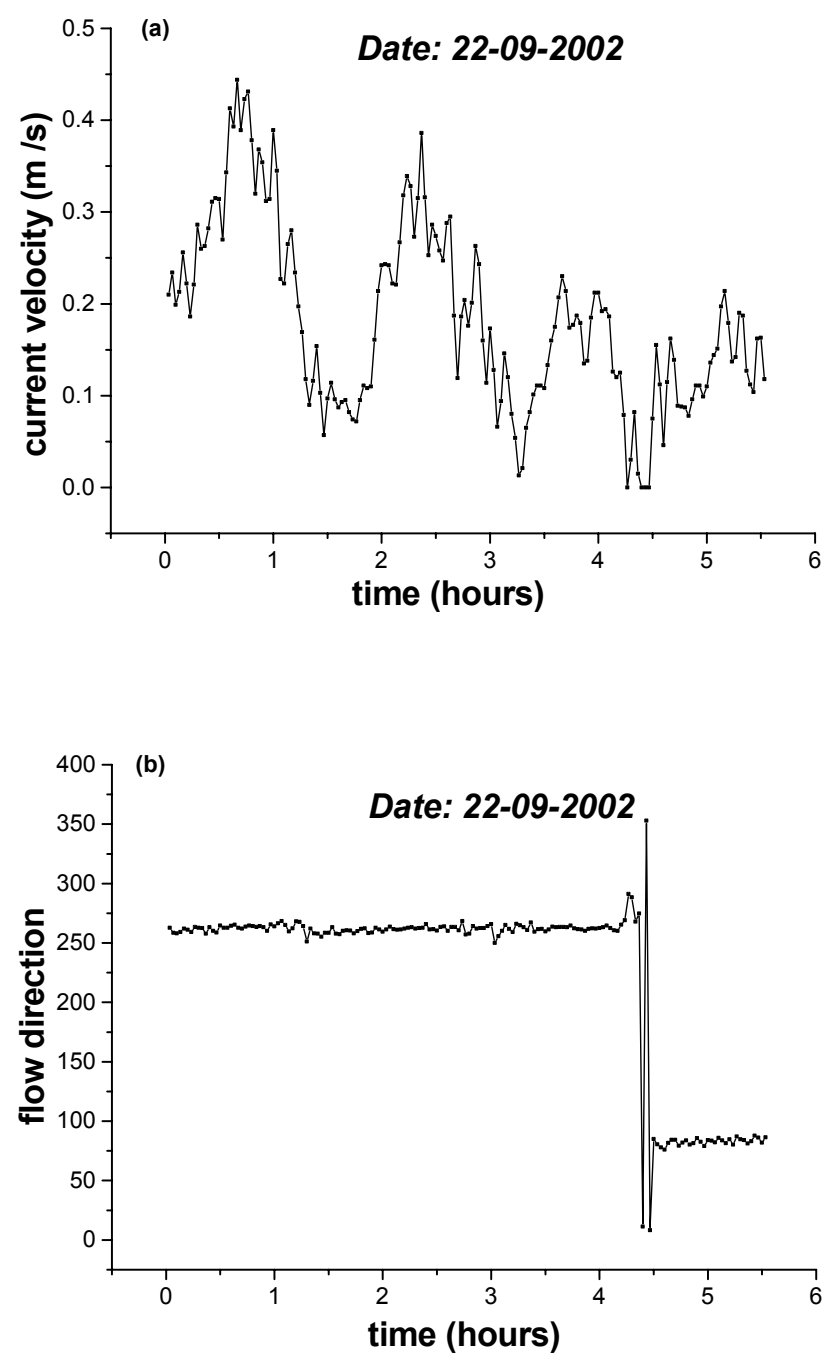

Fig. 5. (a) Current velocity versus time (22 September 2002), (b) Current direction versus time (22 September 2002).

Fig. $4 \mathrm{~b}$ shows that during the first day of the field measurements the current direction, generally varies between $75^{\circ}$ and $275^{\circ}$, indicating that the current changes from east to west and vice versa. However, during most of this time the water moves from west to east. Figure $5 \mathrm{~b}$ shows that during most of the time, corresponding to the second day of the fieldwork (particularly during the first $4.5 \mathrm{~h}$ ) the current direction is around $270^{\circ}$, indicating that the current is heading to the west (i.e. the water moves from east to west). Only the last $1.5 \mathrm{~h}$ of the measurement, the recorded current direction is around $75-80^{\circ}$, indicating that the current is heading to the east.

Concerning the intensity of the current velocity during the field measurements, the following observations can be made: for the first group of the recorded data, the current velocity reaches the maximum value of $0.18 \mathrm{~m} / \mathrm{s}$, while the mean values, corresponding to the main sub-periods at which the current direction remains the same, vary around $0.08 \mathrm{~m} / \mathrm{s}$ (Fig. 4a in combination with Fig. 4b); for the second group of 


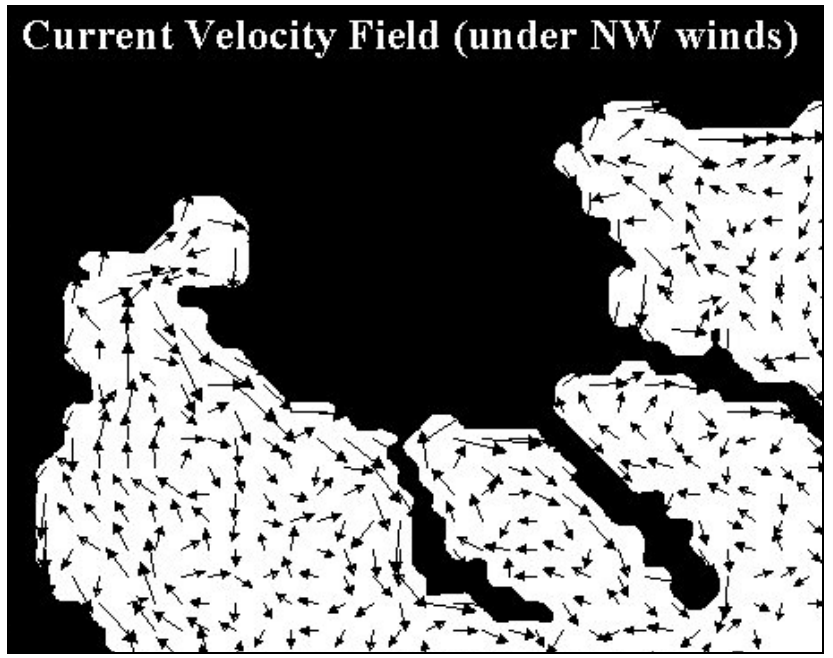

Fig. 6. Depth average currents from the model runs due to NW winds (19 September 2002).

the recorded data the current velocity reaches the maximum value of $0.45 \mathrm{~m} / \mathrm{s}$ while the mean value, corresponding to the first $4.5 \mathrm{~h}$, is $\approx 0.20 \mathrm{~m} / \mathrm{s}$, and the mean value, corresponding to the last $1.5 \mathrm{~h}$, is $\approx 0.11 \mathrm{~m} / \mathrm{s}$ (Fig. $5 \mathrm{a}$ in combination with Fig. 5b).

Summarizing, during the 6-h period of the first day of the fieldwork, multiple successive changes in the current direction (up to 6 to 7 times) were observed while during the 6-h period of the second day of the fieldwork, only one change in the current direction was observed. This strong time variability of the currents' direction in the channel, especially during the 6-h period of the first day of the measurements, could not be due to the tidal influence, since the tide in the region is semidiurnal, which means that the current changes direction only once during this time period. So, it is obvious that the above aforementioned variability of the currents is due to sudden changes in the sea level on the two channel ends, which are caused mainly by the wind forcing.

\subsection{Application of the hydrodynamic model}

Surface wind data are drawn from a valid scientific database provided on http://www.poseidon.ncmr.gr (as well as on http: //www.in.gr). In detail, north and northwestern weak winds $(\mathrm{NW})$ of $\approx 3.5 \mathrm{~m} / \mathrm{s}$ were blowing during the first day of field measurements while moderate southeastern winds (SE) of $\approx 7 \mathrm{~m} / \mathrm{s}$ were blowing during the second day of fieldworks. In this study only the mean wind forcing values and direction, corresponding to the period of the in-situ measurements, were taken into account. The general patterns of the current velocity and elevation fields, computed from the model runs, just after steady-state conditions have been reached, are shown in Figs. 6, 7, 8 and 9. In detail, Figs. 6 and 8 depict the depth average currents' velocity in the basins extending around the channel due to NW and SE winds, respectively. Figure 7 shows a general set down of the sea surface of the

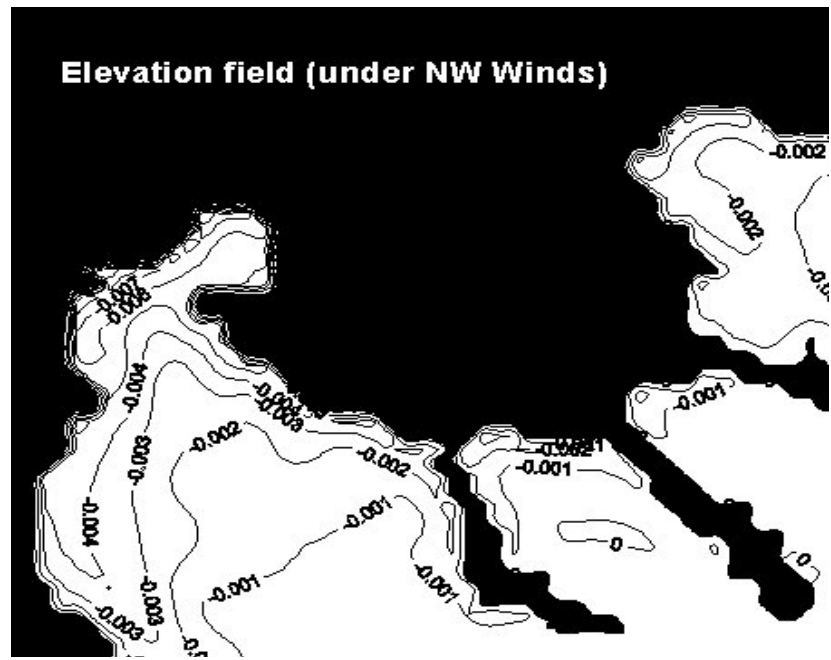

Fig. 7. Surface Elevation field due to northwestern winds (19 September 2002).

two adjacent basins due to NW winds, while Fig. 9 shows a general set up of the sea surface due to SE winds.

The surface elevation difference $\Delta \zeta$, (difference in the free surface elevation level) between the two openings of the channel was then computed from the model simulation. Based on this information the following steps are made for the estimation of the velocity and the water mass exchange between the two gulfs:

a) - The cross section $A$ of the channel is computed from the trapezoid geometry and found equal to $135 \mathrm{~m}^{2}$

- The wet perimeter, $\Pi$, of the channel is computed and found equal to $42 \mathrm{~m}$.

- The hydraulic radius, $R=A / \Pi$, of the channel is finally found $3.2 \mathrm{~m}$.

b) The energy gradient $J$ is taken equal to the gradient of the free surface $\Delta \zeta / L$, produced by the mathematical model of the circulation of the whole basin comprising the two gulfs. More specifically, the difference in the surface elevation between the two ends of the channel is taken as $\Delta \zeta=\zeta_{T o}-\zeta_{T h}$, where the symbol $T_{o}$ denotes the Toroneos Gulf and the symbol $T h$ denotes the Thermaikos Gulf. The simulations for external forcing of the northwestern winds of a mean magnitude of $3.5 \mathrm{~m} / \mathrm{s}$ results ino an elevation difference of $\Delta \zeta=-0.67 \mathrm{~mm}$ indicating seawater movement from the Thermaikos to the Toroneos Gulf. Taking into account the length of the channel $L=1100 \mathrm{~m}$, it is derived that the gradient $J$ is equal to $-0.00067 / 1100$ or $J=-0.61 \times 10^{-6}$. The model application for the southeastern winds of a mean magnitude $7 \mathrm{~m} / \mathrm{s}$ results in an elevation difference of $\Delta \zeta=+0.30 \mathrm{~cm}(+3.0 \mathrm{~mm})$, indicating seawater movement from the Toroneos to the Thermaikos Gulf. Taking into account the length of the channel $L=1100 \mathrm{~m}$, it 


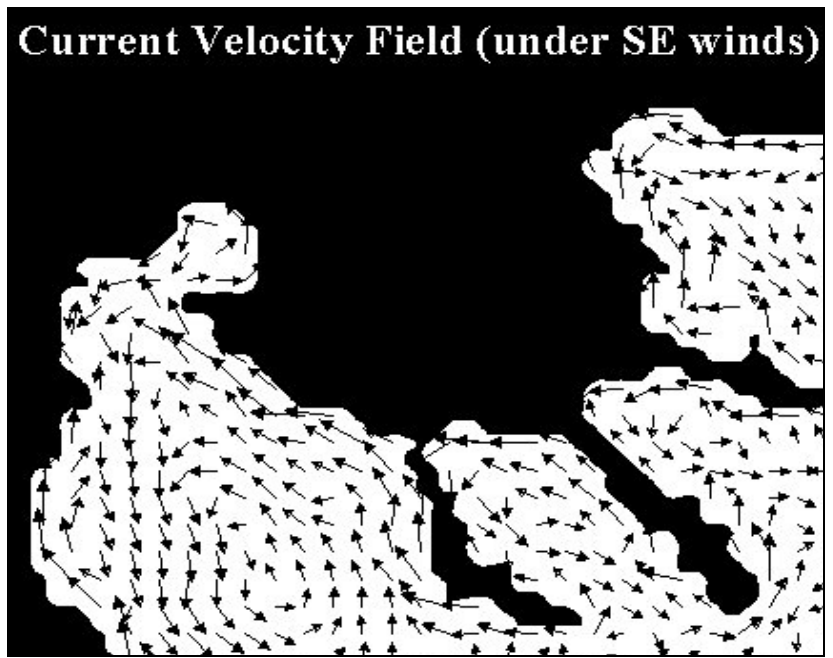

Fig. 8. Depth average currents from the model runs due to SE winds (22 September 2002).

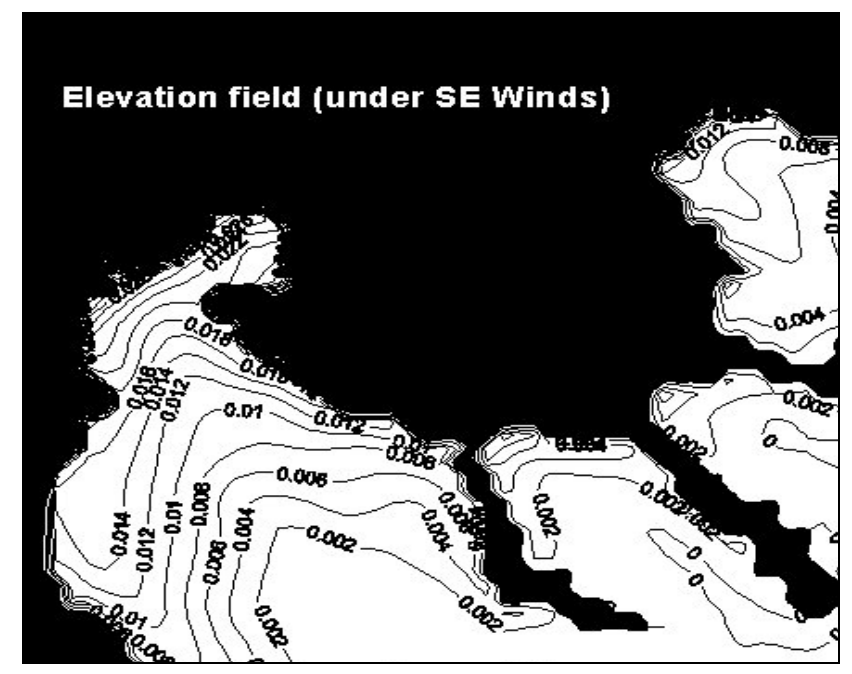

Fig. 9. Surface Elevation field due to southeastern winds (22 September 2002).

is derived that the gradient $J$ is equal to $0.003 / 1100$ or $J=2.72 \times 10^{-6}$.

c) According to bibliographical references, for unlined Earth channels the value of the coefficient/parameter $n$ varies between 0.18 and $0.025 \mathrm{~s} / \mathrm{m}^{1 / 3}$ (Chadwick and Morfett, 1998) i.e. values of $k$ between 5.555 and $40 \mathrm{~m}^{1 / 3} / \mathrm{s}(k=1 / \mathrm{n})$. In Ganoulis (1983) it is found that $k$ generally varies between 12 and $100 \mathrm{~m}^{1 / 3} / \mathrm{s}$ while for stable canals with seafloor material of gravel or sand, or silt and clay, the values of $k$ vary between 30 and $50 \mathrm{~m}^{1 / 3} / \mathrm{s}$. For the present study, $n$ was taken equal to $0.025 \mathrm{~s} / \mathrm{m}^{1 / 3}$.

Replacing the above computed $n, R, J$ values in the Manning formulae, the mean current velocity in the channel, which corresponded to the wind direction and velocity pre-

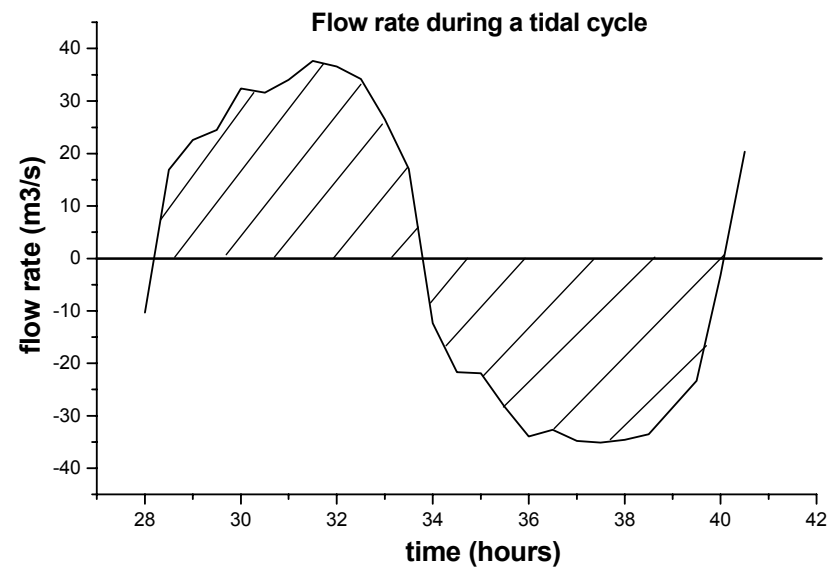

Fig. 10. Flow rate in the channel during a tidal cycle (the time is from the start of simulation).

vailing during the in-situ measurements, were computed as follows:

$$
\begin{aligned}
& u_{N W}=\frac{1}{n} \cdot R^{2 / 3} \cdot J^{1 / 2}=40 \times 3.2^{0.666} \times 0.00000061^{0.5}=0.068 \mathrm{~m} / \mathrm{s} \\
& u_{S E}=\frac{1}{n} \cdot R^{2 / 3} \cdot J^{1 / 2}=40 \times 3.2^{0.666} \times 0.00000272^{0.5}=0.143 \mathrm{~m} / \mathrm{s},
\end{aligned}
$$

where $u_{N W}$ is the mean current velocity due to northwesterly winds and $u_{S E}$ is the mean current velocity due to southeasterly winds.

As it is shown, the computed values of the current velocity along the channel, due to wind forcing for NW and SW winds $(0.07 \mathrm{~m} / \mathrm{s}$ and $0.14 \mathrm{~m} / \mathrm{s}$, respectively), are comparable to the field conditions during the period of the measurements (mean values varying around $0.08 \mathrm{~m} / \mathrm{s}$ for the first case and 0.2 to $0.11 \mathrm{~m} / \mathrm{s}$ for the second case, respectively). The above current values, computed from the model runs, correspond to steady-state conditions, which for the first case was $158.6 \mathrm{~h}$ (6.6 days) while for the second case was $64.7 \mathrm{~h}$ (2.7 days). Of course, the time required for the hydrodynamic to reach quasi-steady-state conditions cannot be precisely determined but we choose to look at the relative change in $K t$ of the current kinetic energy $K$, where $K t=(d / d t(K)) / K$. In this application, it was considered that a steady-state condition was reached as the $K t$ value became less than $1 \%$. It is obvious that taking into account another value of $K t$, bigger than the previous one, steady-state conditions would have been reached in a shorter time period.

It should be noted that tidal influence, was not taken into account, so far. This influence is studied separately in the next section.

For the estimation of the water mass exchange (flow rate), under steady-state conditions and wind forcing the one that prevailed during the field measurements, the following computations are made:

$$
\begin{aligned}
& Q_{N W}=A \times u_{N W} \Rightarrow Q=135 \times 0.068 \Rightarrow Q=9.18 \mathrm{~m}^{3} / \mathrm{s} \\
& Q_{S E}=A \times u_{S E} \Rightarrow Q=135 \times 0.143 \Rightarrow Q=19.37 \mathrm{~m}^{3} / \mathrm{s} .
\end{aligned}
$$


Table 1. Time, $T_{e k}$, required for the hydrodynamic circulation to reach steady-state conditions, Elevation Difference, $\Delta \zeta$, between the two channel openings, Energy gradient $J$, Current Velocity $U$ and Flow Rate $Q$, in the channel for different winds.

\begin{tabular}{lccccc}
\hline Wind direction & $T_{e k}$ & $\Delta \zeta(\mathrm{m})$ & $J=\Delta \zeta / L$ & $U(\mathrm{~m} / \mathrm{s})$ & $Q\left(\mathrm{~m}^{3} / \mathrm{s}\right)$ \\
\hline North winds & $135.3 \mathrm{~h}$ & +0.0039 & $+0.0039 / 1100$ & +0.164 & +22.140 \\
South winds & $135.0 \mathrm{~h}$ & -0.0035 & $-0.0035 / 1100$ & -0.155 & -20.925 \\
East winds & $172.5 \mathrm{~h}$ & +0.0088 & $+0.0088 / 1100$ & +0.246 & +33.210 \\
West winds & $149.4 \mathrm{~h}$ & -0.0076 & $-0.0076 / 1100$ & -0.228 & -30.780 \\
North east winds & $140.3 \mathrm{~h}$ & +0.0099 & $+0.0099 / 1100$ & +0.261 & +35.235 \\
North west winds & $138.3 \mathrm{~h}$ & -0.0026 & $-0.0026 / 1100$ & -0.133 & -17.955 \\
South east winds & $64.7 \mathrm{~h}$ & +0.0030 & $+0.0030 / 1100$ & +0.143 & +19.305 \\
South west winds & $138.0 \mathrm{~h}$ & -0.0086 & $-0.0086 / 1100$ & -0.243 & -32.805 \\
\hline
\end{tabular}

\subsection{Modelling the hydrodynamics due to the tidal effect}

As it was already pointed out, the tide in the region is semidiurnal, which means that the successive current changes recorded during the 6-h period of the in-situ-measurements, are not related to the tidal influence. However, the water mass exchange due to the tidal effects was calculated by a separate numerical integration of the model.

The model runs were based on a mean tidal range of $0.25 \mathrm{~m}$ inciting along the south open sea boundary line of the computational domain. Current velocity and water mass exchange (flow rate) referring to a full tidal cycle is given in Fig. 10. The positive sign indicates flow from the Toroneos to the Thermaikos Gulf (westward flow) while the minus sign indicates flow from the Thermaikos to the Toroneos (eastward flow). The above diagram in Fig. 10 shows that the water mass exchange (flow rate) varies between $\approx-35 \mathrm{~m}^{3} / \mathrm{s}$ and $+35 \mathrm{~m}^{3} / \mathrm{s}$ during the time of a tidal cycle, while the mean values for both the directions are of the order of $20 \mathrm{~m}^{3} / \mathrm{s}$. The maximum values of the flow rate correspond to current velocities of the order of $0.30 \mathrm{~m} / \mathrm{s}(=40 / 135)$ with mean values of $0.15 \mathrm{~m} / \mathrm{s}$.

3.4 Modelling the hydrodynamics due to various wind directions

After the comparative analysis of in-situ measurements and numerical models, all the possible cases of wind directions were examined. This computational stage was considered as supplementary work of the study, so that the water mass exchange, caused by different winds blowing over the area, would be estimated. The tidal forcing was not included in the simulations.

The numerical results produced by the model runs for the eight basic wind directions, i.e. N, S, E, W, NE, NW, SE, SW winds, and mean wind velocity $7 \mathrm{~m} / \mathrm{s}$, are presented in Table $1(n=0,025, R=3.2 \mathrm{~m}$ and $J=\Delta \zeta / L)$. This table presents the time $T_{e k}$ necessary for the circulation to reach steadystate conditions, the elevation difference between the two channel ends $\Delta \zeta$, the energy gradient $J$, the mean current velocity $U$ and the water mass exchange $Q$.
Table 1 shows that the minimum value of the water mass exchange between the two gulfs, under the wind forcing of $7 \mathrm{~m} / \mathrm{s}$, is $\approx 18 \mathrm{~m}^{3} / \mathrm{s}$ while the maximum one is about $35 \mathrm{~m}^{3} / \mathrm{s}$. Of course the direction of the mass exchange also varies, depending on the wind direction as well as the particular time period of the tidal cycle. In more detail, the positive sign indicates water movement from the Gulf of Toroneos towards the Gulf of Thermaikos while the minus sign indicates water movement from the Gulf of Thermaikos towards the gulf of Toroneos.

\section{Summary and conclusions}

A preliminary study of the seawater mass exchange through a navigational channel connecting two adjacent coastal basins is realised. The application concerns the Channel of Potidea that connects the Thermaikos and Toroneos Gulfs, in the North Aegean Sea. Both field measurements (although for short time periods) and numerical experiments have been performed and combined. The recorded field data are compared to the model output for the calibration and the final verification of the model. Based on the verified prognostic ability of the modelling efforts, the study is integrated through the model application for various wind forcings over the extended area of the two gulfs. Using the hydrodynamic information of the sea level variations on both channel ends, the estimation of the water mass exchange between the two gulfs follows. The research showed that the water mass exchange through the channel, due to the wind forcing, varies from 18 to $35 \mathrm{~m}^{3} / \mathrm{s}$. The results refer to steady-state conditions and different wind directions, with mean wind speed equal to $7 \mathrm{~m} / \mathrm{s}$. It was also found that the maximum discharge value due to the mean tidal forcing is of the order of $35 \mathrm{~m}^{3} / \mathrm{s}$, with a mean value of the order of $20 \mathrm{~m}^{3} / \mathrm{s}$. The detailed hydrodynamic study, based on the numerical modelling, revealed that the water mass exchange under mean wind forcing is of the same order as the one induced by the mean tidal forcing, for the specific geographical area and the prevailing meteorological conditions.

The above-presented methodology could have a general applicability and it is useful for the investigation of 
the influence of different forcing factors affecting the water exchange through narrow channels between large semienclosed basins.

Acknowledgements. A. Minas is gratefully acknowledged for his support and help concerning the current recording software as well as the hardware and the calibration of the instrument.

Topical Editor N. Pinardi thanks two referees for their help in evaluating this paper.

\section{References}

Blumberg, A. F. and Mellor, G. L.: A description of a threedimensional coastal circulation model, in: Three-dimensional Coastal Ocean Models, edited by Heaps, N. S., American Geophysical Union, Washington, 1-16, 1987.

Chadwick, A. and Morfett, J.: Hydraulics in Civil and Environmental Engineering, An imprint of Routledge, London and New York, 3rd edition, 1998.

Ganoulis, J.: Hydraulics of pipes' flow (in Greek), Aristotle University of Thessaloniki Press, Thessaloniki, 1983.

Drakopoulos, P. G. and Laskaratos, A.: Modelling the Mediterranean Sea: climatological forcing, J. Mar. Syst., 157-173, 1999.

Koutitas, C.: Mathematical models in Coastal Engineering, Pentech Press Limited, London (UK), 1988.

Koutitas, C.: Three-Dimensional Models of Coastal Circulation: An Engineering Viewpoint, in: Three-dimensional Coastal Ocean Models, edited by Heaps, N. S., American Geophysical Union, Washington, 107-123, 1987.

Karamanos, H. and Polyzonis, E.: The adjacent land area and its potentiality for the fresh water and sediment supply, in: Dynamics of Matter Transfer and Biogeochemical Cycles: Their Modelling in Coastal Systems of the Mediterranean Sea. METROMED Project - A MAST-III ELOISE EU Project, 2nd Annual Scientific Report, 2, 1998.

Kourafalou, V. H.: Process studies on the Po River plume, North Adriatic Sea, J. Geophys. Res., 104, C2, 29 963-29 985, 1999.
Kourafalou, V. H.: River plume development in semi-enclosed Mediterranean regions: North Adriatic Sea and Northwestern Aegean Sea, J. Mar. Syst., 30, 3-4, 181-205, 2001.

Kourafalou, V., Savvidis, Y., Krestenitis, Y., and Koutitas, C.: Modelling Studies on the Processes that Influence Matter Transfer on the Gulf of Thermaikos (NW Aegean), Cont. Shelf Res., 24, 2, 203-222, 2004.

Krestenitis, Y. N., Valioulis, I. A., and Barbopoulos, K. A.: Oceanographic studies of dredging impacts in the Maliakos gulf, J. Mar. Env. Eng., 6, 33-68, 2000.

Krestenitis, Y. N., Valioulis, I. A., Christopoulos, S. P., and Hayder, P. A.: The Rivers Influence on the Seasonal Coastal Circulation of Thermaikos Gulf, Proceedings of the Third International Conference on the Mediterranean Coastal Environment, MEDCOAST 97, 11-14 November, Malta, 1997.

Laskaratos, A., Krestenitis, Y., Triantafulou, G., Kaloumenos, L., and Koutitas, C.: Measurements of the velocity field in cross sections of Thermaikos Gulf with the use of acoustic current tomography, 3rd Panhellenic Symposium of Oceanography and Fishery, Athens, 14-17 May, 1990.

Pinardi, N., Allen, I., Demirov, E., De Mey, P., Korres, G., Laskaratos, A., Le Traon, P.-Y., Maillard, C., Manzalla, G., and Tziavos, C.: The Mediterranean ocean forecasting system: first phase of implementation (1998-2001), Ann. Geophys., 21, 1, 320, 2003,

SRef-ID: 1432-0576/ag/2003-21-3.

Savvidis, Y. G., Koutitas, C. G., and Krestenitis, Y. N.: Development and application of a three-dimensional cohesive sediment transport mathematical model, J. Mar. Env. Eng., 6, 229-255, 2001.

Ursella, L. and Gacic, M.: Use of the Acoustic Doppler Current Profiler (ADCP) in the study of the circulation of the Adriatic Sea, Ann. Geophys., 19, 1183-1193, 2001,

SRef-ID: 1432-0576/ag/2001-19-1183.

Valioulis, I. A. and Krestenitis, Y. N.: Modelling the water mass circulation in the Aegean Sea. Part I: wind stresses, thermal and haline fluxes, Ann. Geophys., 12, 794-807, 1994,

SRef-ID: 1432-0576/ag/1994-12-794. 